\title{
Neonatal Listeriosis-Infection Leading to Death of the Newborn. A Case Report
}

\author{
Piotr Rzepniewski, Natalia Gołuchowska*, Ewa Głuszczak Idziakowska and Bożena Kociszewska \\ Najman \\ Department of Neonatology, University Clinical Center of the Medical University of Warsaw, Poland
}

*Corresponding author: Natalia Gołuchowska, Department of Neonatology, University Clinical Center of the Medical University of Warsaw, Poland

\begin{abstract}
ARTICLE INFO
Received: 峟 July 09, 2020

Published: 幽 August 04, 2020

Citation: Piotr R, Natalia G, Ewa Głuszczak

\section{ABSTRACT}

Listeriosis is rare and potentially fatal disease of newborn. Maternal listeriosis is presented with nonspecific symptoms, therefore is often misdiagnosed, and can lead to severe complications, such as spontaneous abortion, stillbirth, preterm delivery, neonatal sepsis and death. We report a case of the newborn with listeriosis, who despite intensive treatment, died.
\end{abstract} I, Bożena Kociszewska N. Neonatal Listeriosis-Infection Leading to Death of the Newborn. A Case Report. Biomed J Sci \& Tech Res 29(2)-2020. BJSTR. MS.ID.004778.
Keywords: Listeria Monocytogenes; Newborn; Neonatal Listeriosis; Fatal Infection

\section{Introduction}

Listeria monocytogenes is an aerobic, Gram-positive bacteria that is widespread in the environment. It rarely contributes to infection of the general population; however, it is a crucial cause of possibly fatal bacteremia among some groups, including newborns, pregnant women, elderly and people taking immunosuppressive drugs [1]. Listeria has a wide range of tolerance for temperature (0$45^{\circ} \mathrm{C}$ ), $\mathrm{pH}$, and the salt concentration [2]. Also, it is highly resistant to low temperatures. The main source of infection is contaminated food, especially raw meat, unpasteurized dairy products, ready meals, and unwashed fruit and vegetables [3]. The risk of bacteremia caused by listeria in case of pregnant women is estimated as 20 times higher and $2 / 3$ of children born to such mothers develops clinical listeriosis $[4,5]$. Infection in newborns occurs through the placenta, aspiration of contaminated amniotic fluid, or in the less common case of infection by another newborn. Despite applying the right course of treatment, the death rate among patients with listeriosis is estimated at $30 \%[4,6]$. The case of a newborn, born and treated in our clinic, whose death was caused by maternal infection of listeria monocytogenes is presented below.

\section{Case Report}

The male newborn was born in our clinic from the first pregnancy in the $26^{\text {th }}$ week of pregnancy in natural birth. The course of pregnancy was complicated by the mother's infection with the following symptoms: fever up to $39^{\circ} \mathrm{C}$, chills, and elevated laboratory markers (CRP $15.0 \mathrm{mg} / \mathrm{dl}$ - norm up to 1 ). The clean amniotic fluid was released 10 minutes before the birth. The child was born in extremely severe condition, evaluated in the Apgar score for 2-3 points ( $\mathrm{pH}$ of cord blood 7,0, BE-15). Birth weight was $1150 \mathrm{~g}$ (98.centile), length $41 \mathrm{~cm}$ (100.centile). The newborn was intubated with NeoPuff infant resuscitator two minutes after being born. Average oxygen saturation was $60-70 \%$ with $100 \%$ FiO2 ventilation. 25 minutes after the birth $200 \mathrm{mg} / \mathrm{kg}$ of Curosurf was administered intratracheally and in turn, there was a slight improvement and saturation reached $80-85 \%$. The procedure of assisted ventilation replacement was continued, initially conventional and then in oscillatory ventilation mode (HFO).

A Chest X-ray showed RDS grade IV. Increasing oxygen demand up to $100 \%$ in the respiratory mixture was again observed and the child developed severe mixed acidosis. Eight hours after the birth, the second dose of surfactant was given. The control X-ray showed a slight improvement in lung aeration. The child was circulatory insufficient from birth. An echographic examination did not reveal any irregularities of the heart's anatomy. The vascular bed was filled with crystalloids and colloids, a constant infusion of three catecholamines was used without any improvement. Hypotension 
and increasing metabolic acidosis persisted despite the use of natrium bicarbonicum for continuous infusions and bolus infusions. Despite intensive treatment of circulatory and respiratory failure and forced diuresis, no improvement in the child's condition was noted, anuria was observed. Physical examination revealed increasing scleroderma edema. Due to infectious perinatal history and extremely severe general condition of the child, blood culture was collected and empirical antibiotic therapy with Ampicillin and Gentamicin was initiated.

Laboratory tests showed severe leukopenia with neutropenia, lymphocytic smear, and CRP on day 1 was $5.3 \mathrm{mg} / \mathrm{dl}$ (norm up to 1). Due to the telephone information obtained from microbiology, it was revealed that the blood culture indicated an increase in Listeria monocytogenes. The newborn was treated with Ampicillin at doses as in meningitis and with Gentamycin. Additionally, in the child's blood tests, anemia, thrombocytopenia, and coagulological disorders were found. The newborn was transfused with fresh frozen plasma, cryoprecipitate, irradiated leukocyte-poor packed red blood cells and radioactive irradiated leukocyte-poor platelet concentrate in accordance with the blood type. Imaging test of the central nervous system revealed bleeding to all ventricles of the brain, bilateral $4^{\text {th }}$-degree periventricular hemorrhage and bleeding to the right cerebellar hemisphere (area diameter $5-10 \mathrm{~mm}$ ). Due to massive brain bleeding and serious coagulological disorders, lumbar puncture was not performed. Ultrasound of the abdomen showed signs of centralization of circulation. Despite intensive treatment, the newborn's condition deteriorated, and the child died within the second day of being alive.

\section{Conclusion}

Neonatal listeriosis is a rare but serious disease with high mortality $[1,4,6]$. A different course of infection may suggest that many cases and deaths caused by Listeriosis remain undiagnosed. The number of perinatal infections may be higher than indicated in the statistics due to the lack of blood cultures in case of miscarriages and stillbirths [7-9]. In our case, it is worth emphasizing that in the first culture of the patient's mother, which was taken prior to delivery and from the cervical canal, the colonization of Candida albicans and Staphylococcus epidermidis were found. After 24 hours, it was taken again due to severe intrauterine infection diagnosed in the child. At that time, few Listeria monocytogenes were cultured in cultures of lochia. It indicates that there are diagnostic difficulties concerning pregnant women with listeria infection. Fever and flu-like symptoms are the most common symptoms in pregnant women, while newborns most often have sepsis, pneumonia and meningitis [10].
Bilateral periventricular hemorrhage and cerebellar hemorrhage are also characteristic of neonatal listeriosis, as it was found in our patient. A whole-body rash, often described in neonates with listeriosis, was not present in our patient [11]. Taking into consideration the serious course of Listeriosis in newborns, pregnant women are advised to use infection prevention measures during pregnancy. It is crucial for pregnant women to cook products of animal origin as well as avoid unpasteurized milk, soft cheeses such as feta, brie, camembert $[10,12]$. Ampicillin is usually taken into consideration in case of an indication of infection of listeria in newborns. Because of its delayed effect on the bacteria, co-administration of an aminoglycoside antibiotic is advised. Antibiotics that are mentioned above should be applied in the same dose as in case of meningitis, even if the CNS has not been seized. Our patient is an example that a newborn infection of listeria is still a very serious challenge for doctors. Although the most optimal pattern of treatment was applied, the patient could not be saved.

\section{References}

1. Mandell GL, Bennett JE, Dolin R (2005) Mandell, Douglas and Bennett's principal and practice of infectious diseases. $6^{\text {th }}$ (Edi.). Philadelphia: Elsevier Churchill Livingstone pp. 2478-2484.

2. Liu D (2006) Identification, subtyping and virulence determination of Listeria monocytogenes, an important foodborne pathogen. J Med Microbiol 55(Pt 6): 645-659.

3. Pickering LK, Baker CJ, Long SS, McMillan JA (2006) Red Book: 2006 Report of the Committee on Infectious Diseases, $27^{\text {th }}$ (Edi.). Emerg Infect Dis 12(12): 2003-2004.

4. Siegman Igra Y, Levin R, Weinberger M, Golan Y, Schwartz D, et al. (2002) Listeria monocytogenes infection in Israel and review of cases worldwide. Emerg Infect Dis 8(3): 305-310.

5. Bortolussi R (1990) Neonatal listeriosis. Semin Perinatol 14(4Suppl 1): 44-48.

6. Zach T, Anderson Berry AL (2009) Listeria infection. Pediatrics: General Medicine.

7. Remington J, Klein J, Wilson C, Nizet V, Maldonado Y (2011) Infectious diseases of the fetus and newborn infant. $7^{\text {th }}$ (Edi.). Philadelphia: Elsevier Saunders pp. 470-486.

8. Kaufman D, Fairchild KD (2004) Clinical microbiology of bacterial and fungal sepsis in very-low-birth-weight infants. Clin Microbiol Rev 17(3): 638-680.

9. Simonsen KA, Anderson Berry AL, Delair SF, Davies HD (2014) Clin Microbiol Rev 27(1): 21-47.

10. Kylat RI, Bartholomew A, Cramer, Bader MY (2016) Neonatal listeriosis: Uncommon or misdiagnosed? Journal of Neonatal-Perinatal Medicine 9(3): 313-316.

11. Gaschignard J, Levy C, Romain O, Cohen R, Bingen E, et al. (2011) Neonatal Bacterial Meningitis: 444 cases in 7 years. Pediatr Infect Dis J 30(3): 212-217.

12. Mandell GL, Bennett JE, Dolin R (2010) Mandell, Douglas, and Bennett's Principles and Practice of Infectious Diseases. $7^{\text {th }}$ (Edi.). Philadelphia: Elsevier Churchill Livingstone pp. 2707-2713. 
ISSN: 2574-1241

DOI: 10.26717/BJSTR.2020.29.004778

Natalia Gołuchowska. Biomed J Sci \& Tech Res

(C) This work is licensed under Creative

Submission Link: https://biomedres.us/submit-manuscript.php

$\begin{array}{ll}\text { BIOMEDICAL } & \text { Assets of Publishing with us } \\ \text { RESEARCHES } & \text { - Global archiving of articles } \\ \text { - Immediate, unrestricted online access } & \text { - Rigorous Peer Review Process } \\ & \text { - Authors Retain Copyrights } \\ \end{array}$

